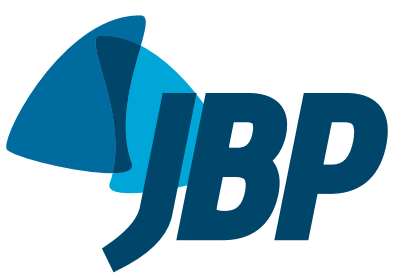

\title{
The paradox of asthma: neglect, burden, and big data
}

\author{
Rafael Stelmach ${ }^{1}$, Álvaro Augusto $\mathrm{Cruz}^{2}$
}

English is the lingua franca of scientific communication and, as such, provides words that are pregnant with meaning and symbolism but also challenging; paradoxically, such words often pave the way for solutions and innovations. Asthma is the most prevalent chronic lung disease and is per se a paradoxical disease: clinical control and good health-related quality of life can be achieved, and the risk of death is minimal or nonexistent. However, in numerous studies conducted in Brazil or other countries where disease control and treatment adherence are poor, the word "asthma" is often accompanied by the concept words "neglect" and "burden".

In an editorial published in the JBP in 2014, PerezPadilla et al. ${ }^{(1)}$ drew attention to the neglected burden of respiratory diseases, as a result of delayed diagnosis, fragmented reporting of morbidity and mortality, and compartmentalization of respiratory care, proposing that integrated primary health care programs be implemented in low- and middle-income countries. The reported prevalence of asthma (or asthma symptoms) in such countries is low; however, there is evidence that these data underestimate specific phenotypes, which might be related to hygiene, pollution, or lack of health resources/ infrastructure. (2) There is no longer any doubt that the aforementioned factors influence disease severity and prognosis in children with obstructive lung disease in early childhood. ${ }^{(1,2}$

The incidence of asthma in Brazil is believed to be approximately $10 \%$; however, given the lack of nationwide epidemiological data, this rate is based on scattered reports. In contrast, the prevalence of asthma in Brazil is well known because of successive population-based surveys conducted under the auspices of the International Study of Asthma and Allergies in Childhood project.(2) With regard to asthma control, Marchioro et al. ${ }^{(3)}$ conducted a population-based survey and found that asthma is uncontrolled in the vast majority of asthma patients in Brazil, and that patients are more likely to use oral corticosteroids and rescue bronchodilators as the treatment of choice for asthma, despite all efforts by asthma management programs and centers in Brazil advocating maintenance treatment with inhaled corticosteroids for 20 years. ${ }^{(4)}$ Another paradox is that although asthma medications are provided free of charge in Brazil-apparently the only major economy in the world in which this is done-this has no clear impact on treatment adherence or disease control, as evidenced by a nationwide survey showing that nearly $50 \%$ of all young individuals with asthma symptoms have never received a diagnosis of asthma. ${ }^{(5)}$
Not all is as gloomy as it might seem. The Brazilian Sistema Único de Saúde (SUS, Unified Health Care System), which was established by the 1988 Federal Constitution (the so-called "citizen" Constitution), broke with the historical logic of the dichotomy between prevention and treatment in public health. I will not dwell on the achievements and shortcomings of the SUS since it was first established, but I believe that one of its greatest achievements was the Departamento de Informática do SUS (DATASUS, Information Technology Department of the SUS). Albeit rarely explored by researchers in Brazil, the DATASUS is a classic example of big data, which, according to Wikipedia, ${ }^{(6)}$ is a term for large and complex data sets. Big data is characterized by 5 v's: velocity; volume; variety; veracity; and value. Analysis of these large data sets can reveal new correlations to spot business trends, prevent diseases, and combat crime, among others. ${ }^{(6)}$

In the previous and current issues of the JBP, two studies used the DATASUS database (particularly the TabWin program) in order to assess trends in hospital costs and in-hospital morbidity, as well as asthma mortality, in the period between the end of the 20th century and a few years ago in Brazil. Graudenz et al. (7) showed a marked $(65 \%)$ decrease in the asthma mortality rate in the 0 - to 34-year age bracket; however, the asthma mortality rate remained at $9-10 \%$ in the 5- to 35 -year age bracket, with a remarkable decrease in children under 5 years of age (from 3.5 deaths per 100,000 population to 0.5 deaths per 100,000 population). However, the absolute number of deaths in the 0 - to 35-year age bracket remained at 2,000-2,500 per year, with a disturbing mean of more than 6 asthma-related deaths per day during the study period. In the current issue of the JBP, a descriptive study presents official longitudinal data on the impact of asthma in Brazil between 2008 and 2013. (8) The data were collected from the DATASUS database, including data on number of hospitalizations, mortality, and hospitalization costs. A geographic subanalysis was also performed, based on data from the Brazilian Institute of Geography and Statistics database. The study describes all TabWin parameters used for data collection and shows the following: 2,047 people died from asthma in Brazil (5 deaths/day), with more than 120,000 hospitalizations/year; although the absolute numbers of deaths and hospitalizations decreased by $10 \%$ and $36 \%$, respectively, the in-hospital mortality rate increased by approximately $25 \%$ in the study period; the northern/northeastern and southeastern regions had the highest asthma-related hospitalization and in-hospital mortality rates, respectively; during the study period, 
the cost of asthma-related hospitalizations to the SUS was US\$ 170 million. ${ }^{(8)}$

The results of the two aforementioned studies ${ }^{(7,8)}$ corroborate the volume, veracity, and value of the DATASUS "big data" in epidemiological surveys showing past and present asthma burden and neglect in Brazil. Although asthma-related hospitalizations and deaths have decreased by nearly $70 \%$ in children under 5 years of age-which might be due to an overall reduction in child mortality in Brazil-the deaths of 3-5 patients/day (depending on the age bracket) and the 100,000 hospitalizations per year are sufficient cause for concern to warrant social media campaigns such as those launched by the Global Initiative for Asthma in Brazil in order to raise awareness of the problem. ${ }^{(9)}$

In Brazil, asthma control programs under which patients with uncontrolled asthma are identified, are monitored, and receive pharmacological treatment have been shown to be successful in reducing hospitalizations and direct and indirect costs to patients and the SUS. ${ }^{(10)}$ However, in a country as large and geographically varied as Brazil, where 20 million people are estimated to have asthma, primary health care interventions are lacking. In adults, the burden of asthma is similar to that of diabetes and cardiovascular disease, being even higher in children and adolescents. However, although diabetes and cardiovascular disease have long been the targets of primary health care policies in Brazil, asthma and other chronic respiratory diseases are not.

There is no doubt that the DATASUS database and other public databases in Brazil are essential resources for generating knowledge and providing the basis for public health policies, as demonstrated in the aforementioned studies. ${ }^{(7,8)}$ Analysis of data from the DATASUS database should be encouraged in graduate programs because access to the database is open and free, being less costly than population-based surveys. In a recent ecological study of time trends in all Brazilian municipalities, the authors analyzed data collected from the DATASUS database and found that asthma morbidity and mortality were associated with the proportion of individuals living in urban areas, ${ }^{(11)}$ a finding that allows the planning of household and community strategies to combat asthma.

\section{REFERENCES}

1. Pérez-Padilla $R$, Stelmach $R$, Soto-Quiroz M, Cruz AA. Fighting respiratory diseases: divided efforts lead to weakness. J Bras Pneumol. 2014;40(3):207-10. https://doi.org/10.1590/S180637132014000300001

2. Cruz ÁA, Stelmach R, Ponte EV. Asthma prevalence and severity in low-resource communities. Curr Opin Allergy Clin Immunol. 2017;17(3):188-93. https://doi.org/10.1097/ACI.0000000000000360

3. Marchioro J, Gazzotti MR, Nascimento OA, Montealegre F, Fish J, Jardim JR. Level of asthma control and its relationship with medication use in asthma patients in Brazil. J Bras Pneumol. 2014;40(5):487-94 https://doi.org/10.1590/S1806-37132014000500004

4. Stelmach R, Cerci Neto A, Fonseca AC, Ponte EV, Alves G, AraujoCosta IN, et al. A workshop on asthma management programs and centers in Brazil: reviewing and explaining concepts. J Bras Pneumol. 2015;41(1):3-15. https://doi.org/10.1590/S1806 37132015000100002

5. Barreto ML, Ribeiro-Silva Rde C, Malta DC, Oliveira-Campos M, Andreazzi MA Cruz AA. Prevalence of asthma symptoms among adolescents in Brazil: National Adolescent School-based Health Survey (PeNSE 2012). Rev Bras Epidemiol. 2014;17 Suppl 1:106-15. https://doi.org/10.1590/1809-4503201400050009
6. Wikimedia Commons [homepage on the Internet]. San Francisco: Wikimedia Foundation [updated 2017 May 1; cited 2017 May 21]. Big data. Available from: https://pt.wikipedia.org/wiki/Big_data

7. Graudenz GS, Carneiro DP, Vieira RP. Trends in asthma mortality in the 0 - to 4-year and 5- to 34-year age groups in Brazil. J Bras Pneumol. 2017;43(1):24-31. https://doi.org/10.1590/s180637562015000000253

8. Cardoso TA, Roncada C, Silva ER, Pinto LA, Jones MH, Stein RT et al. The impact of asthma in Brazil: a longitudinal analysis of data from a Brazilian national database system. J Bras Pneumol. 2017;43(3):163-168.

9. GINAnoBrasil [homepage on the Internet]. Iniciativa Global Contra a Asma [cited 2017 May 1]. Available from: www.ginanobrasil.org.br

10. Souza-Machado C, Souza-Machado A, Franco R, Ponte EV, Barreto $\mathrm{ML}$, Rodrigues LC, et al. Rapid reduction in hospitalisations after an intervention to manage severe asthma. Eur Respir J. 2010;35(3):51521. https://doi.org/10.1183/09031936.00101009

11. Ponte EV, Cruz AA, Athanazio $R$, Carvalho-Pinto $R$, Fernandes FL, Barreto $\mathrm{ML}$, et al. Urbanization is associated with increased asthma morbidity and mortality in Brazil. Clin Respir J. 2016 Jul 12. [Epub ahead of print]. https://doi.org/10.1111/crj.12530 